\title{
Cholinergic drugs affect novel object recognition in rats: relation with hippocampal EEG?
}

Citation for published version (APA):

Sambeth, A., Riedel, W., Smits, L., \& Blokland, A. (2007). Cholinergic drugs affect novel object recognition in rats: relation with hippocampal EEG? European Journal of Pharmacology, 572, 151-159. https://doi.org/10.1016/j.ejphar.2007.06.018

Document status and date:

Published: 01/01/2007

DOI:

10.1016/j.ejphar.2007.06.018

Document Version:

Publisher's PDF, also known as Version of record

Document license:

Taverne

\section{Please check the document version of this publication:}

- A submitted manuscript is the version of the article upon submission and before peer-review. There can be important differences between the submitted version and the official published version of record.

People interested in the research are advised to contact the author for the final version of the publication, or visit the DOI to the publisher's website.

- The final author version and the galley proof are versions of the publication after peer review.

- The final published version features the final layout of the paper including the volume, issue and page numbers.

Link to publication

\footnotetext{
General rights rights.

- You may freely distribute the URL identifying the publication in the public portal. please follow below link for the End User Agreement:

www.umlib.nl/taverne-license

Take down policy

If you believe that this document breaches copyright please contact us at:

repository@maastrichtuniversity.nl

providing details and we will investigate your claim.
}

Copyright and moral rights for the publications made accessible in the public portal are retained by the authors and/or other copyright owners and it is a condition of accessing publications that users recognise and abide by the legal requirements associated with these

- Users may download and print one copy of any publication from the public portal for the purpose of private study or research.

- You may not further distribute the material or use it for any profit-making activity or commercial gain

If the publication is distributed under the terms of Article $25 \mathrm{fa}$ of the Dutch Copyright Act, indicated by the "Taverne" license above, 


\title{
Cholinergic drugs affect novel object recognition in rats: Relation with hippocampal EEG?
}

\author{
Anke Sambeth *, Wim J. Riedel, Laura Th. Smits, Arjan Blokland \\ Faculty of Psychology and Brain and Behavior Institute, Maastricht University, P.O. Box 616, 6200 MD Maastricht, The Netherlands
}

Received 26 February 2007; received in revised form 11 June 2007; accepted 12 June 2007

Available online 27 June 2007

\begin{abstract}
This study examined the role of cognitively enhancing cholinergic drugs on both object memory and brain activity in rats, as well as the possible relation between the two measures. A group of twenty-four animals was used for assessing object recognition. In another group of eight rats, an electrode was implanted into the dorsal hippocampus to record an electroencephalogram (EEG) and auditory evoked potentials (AEP). In both groups, animals were treated with saline, $0.1 \mathrm{mg} / \mathrm{kg}$ scopolamine, $0.1 \mathrm{mg} / \mathrm{kg}$ methylscopolamine, $3 \mathrm{mg} / \mathrm{kg}$ donepezil, donepezil combined with scopolamine, $0.1 \mathrm{mg} / \mathrm{kg}$ nicotine, and nicotine combined with scopolamine. Scopolamine, but not methylscopolamine, impaired object recognition. Both donepezil and nicotine reversed this impairment. The N1 and N2 components of the AEP became closer to baseline after scopolamine, which was not reversed by donepezil or nicotine. Scopolamine increased the theta frequency in the EEG. When combined with donepezil, theta increased even more. Conversely, nicotine reversed the theta increment to control level. It is suggested that scopolamine caused a decrement in arousal in this study. Furthermore, the current results suggest a relation between EEG and object memory after cholinergic drug treatment. However, there was a clear dissociation between memory performance and EEG after combined treatment with drugs, which makes additional research where EEG and performance measures are co-registered imperative.
\end{abstract}

(C) 2007 Elsevier B.V. All rights reserved.

Keywords: Acetylcholine; Animal model; Auditory evoked potential (AEP); Donepezil; Electroencephalogram (EEG); Nicotine; Scopolamine

\section{Introduction}

Previous studies have shown that the object recognition task in rats is highly sensitive to psychoactive drug treatments. Various drugs such as acetylcholinesterase inhibitors can improve object memory performance in these animals (Lieben et al., 2005; Prickaerts et al., 2005). This suggests that such drugs may also be useful in treating memory impairments in humans. However, clear evidence for a reliable memory enhancing effect of these drugs in humans is lacking, which is possibly related to the discrepancy between the large numbers of animal studies showing memory improvement after treatment

\footnotetext{
* Corresponding author. Department of Neurocognition, Faculty of Psychology, Maastricht University, P.O. Box 616, NL-6200 MD Maastricht, The Netherlands. Tel.: +31 433881757; fax: +31433884125 .

E-mail address: anke.sambeth@psychology.unimaas.nl (A. Sambeth).
}

with acetylcholinesterase inhibitors, whereas there are only a limited number of human studies showing memory enhancing effects of drugs. Studies using rats as subjects show that acetylcholinesterase inhibitors such as metrifonate, rivastigmine, and donepezil can reverse drug-induced memory impairments (Bejar et al., 1999; Lieben et al., 2005; van der Staay and Bouger, 2005; Yamada et al., 2005). However, only Snyder and colleagues (Snyder et al., 2005) were able to improve a scopolamine-induced memory impairment in healthy elderly volunteers using donepezil, whereas a single dose of rivastigmine even impaired recognition memory in the study of Wezenberg et al. (Wezenberg et al., 2005). Furthermore, Mumenthaler and colleagues showed that nicotine and donepezil mainly improved sustained attention processes rather than learning and memory (Mumenthaler et al., 2003). It must be noted, however, that acetylcholinesterase inhibitors may improve memory to some extent in clinical populations (e.g., Birks, 2006; Yoo et al., in press). 
EEG characteristics show great similarities across species. For example, alertness is associated with fast frequencies in the EEG (e.g., beta activity), whereas non-REM sleep and drowsiness are characterized by slower waves (synchronized firing of cortical neurons). Also, evoked potentials (EPs) show great correspondence between rats and man (Sambeth et al., 2003, 2004; Sambeth and Maes, 2006). In both species, the short latency EP components are related to the processing of the physical properties of a stimulus, whereas the later components are associated with more endogenous processing, e.g., the psychological processes involved in the stimulus event (e.g., Sambeth et al., 2003; Sambeth and Maes, 2006). Therefore, drug-induced changes in EEG characteristics in animals may be used to predict central activity of drugs in humans. Clearly, such an approach can also be used if first a relation between EEG and memory performance can be found in animals.

Previous work has shown that drugs affect EEG characteristics in humans and rodents in a similar manner (Coenen and Van Luijtelaar, 2003; Dimpfel, 2005; Dimpfel et al., 1992; Jongsma et al., 1998a,b). However, whether drug effects on memory performance are related with EEG characteristics in rats has not been tested yet. Therefore, we evaluated drug effects in an object recognition task (memory) and examined the effects of the same drugs on hippocampal auditory evoked potentials (AEP) and theta activity in two groups of rats. Auditory stimuli were chosen, since they reveal a strong correspondence between rats and humans (Sambeth and Maes, 2006; Sambeth et al., 2004). Furthermore, Campbell and coworkers (Campbell et al., 1995) have suggested that a disruption of muscarinic cholinergic receptor activation in the extralemniscal auditory pathways will lead to changes in AEP components (in this study, acetylcholine was manipulated).

We used scopolamine to induce a memory impairment using an object recognition task. Methyl-scopolamine, which only differs from scopolamine in that it does not cross the bloodbrain barrier, was used as a control. Both donepezil, an acetylcholinesterase inhibitor, thereby preserving synaptic and presynaptic acetylcholine, and nicotine, a nicotinic receptor agonist, were administered alone or together with scopolamine in order to examine whether they were able to reverse both the scopolamine-induced memory impairments and the scopolamine effects on the AEP and the EEG. The EEG was recorded from the dorsal hippocampus, since previous work has shown this brain area to be involved in object recognition (Broadbent et al., 2004; Clark et al., 2000; Prickaerts et al., 2002a).

\section{Materials and methods}

\subsection{Animals}

The study was performed in accordance with the guidelines of the European Community for the use of experimental animals. Approval of the local ethical committee of the Maastricht University for animal experiments was obtained. Eight (for EEG study) and 24 (for memory study) 3-month-old male Wistar rats (Harlan, Horst, The Netherlands) served as subjects. The animals were singly housed in standard Makrolon cages on sawdust bedding in an air-conditioned room (around $21^{\circ} \mathrm{C}$ ). They were maintained on a $12-12 \mathrm{~h} \mathrm{light-dark} \mathrm{cycle}$ with lights off at $5.00 \mathrm{a}$ am. and had unlimited access to food and water. The rats also had a block of wood in their cages to sit on or to gnaw on. Rats were housed in the same room as where they were tested. A radio, which was playing softly, provided background noise.

\subsection{Surgical procedures and recordings of EEG study}

Animals were anesthesized with ketamine $50 \mathrm{mg} / \mathrm{kg}$ i.m. and additionally received an s.c. injection of the muscle relaxant xylazine $4 \mathrm{mg} / \mathrm{kg}$. Next, they were placed in a stereotaxic frame. After exposing the skull, the animals received several drops of the local anesthetic lidocaine before the bregma intersection was identified. One active lead in the dorsal hippocampus (anteriorposterior -3.2, medial-lateral 1.6, dorsal-ventral -2.6) was inserted, related to bregma. It was referenced to the cerebellum. The ground was also placed in the cerebellum. Three screws and dental acrylic cement were employed to fix the electrode on the skull surface. After the surgery, the animals received an injection of Temgesic $(0.1 \mathrm{mg} / \mathrm{kg}$, s.c. $)$ to reduce pain. Next, they were allowed to recover for at least two weeks.

Field potentials (electroencephalogram, EEG) were filtered between 1 and $133 \mathrm{~Hz}$ and sampled at $1000 \mathrm{~Hz}$. The results were stored on a personal computer and analyzed using Neuroscan software.

Each session started with the injection of the drugs. Thirty minutes later, rats were attached to the EEG equipment and EEG was visually checked. This was followed by the presentation of 120 auditory stimuli. They had a duration of $500 \mathrm{~ms}$, a frequency of $2500 \mathrm{~Hz}$ and an intensity of $80 \mathrm{~dB}$. The inter-stimulus interval was $2000-4000 \mathrm{~ms}$.

\subsection{Object recognition memory and procedure of memory study}

The object recognition test was performed as described elsewhere (e.g., Prickaerts et al., 2005, 2002b). The apparatus consisted of a circular arena, $83 \mathrm{~cm}$ in diameter. Half of the $40 \mathrm{~cm}$ high wall was attached with a black and white plastic topping, the other half of transparent polyvinyl chloride. Fluorescent red tubes and a light bulb provided a constant illumination of about 20 lux on the floor of the apparatus. The light intensity was equal in the different parts of the apparatus. Two objects were placed in a symmetrical position about $10 \mathrm{~cm}$ away from the wall. Each object was available in triplicate. Eight different sets of objects were used. The different objects were; 1 ) a cone consisting of a gray polyvinyl chloride base (maximal diameter $18 \mathrm{~cm}$ ) with a collar on top made of brass (total height $16 \mathrm{~cm}$ ), 2) a bottle of brown glass (diameter $10 \mathrm{~cm}$, height $22 \mathrm{~cm}$ ) filled with water, 3) a massive metal cube $(10.0 \times 5.0 \times 7.5 \mathrm{~cm})$ with two holes (diameter $1.9 \mathrm{~cm}$ ), 4) a massive aluminum cube with a tapering top $(13.0 \times 8.0 \times 8.0 \mathrm{~cm}), 5)$ a stoneware flowerpot with a $1 \mathrm{~cm}$ opening on top (maximal diameter $12.0 \mathrm{~cm}$ ), 6) a round varnished vase with a slender neck (maximal diameter round part $9.0 \mathrm{~cm}$, height $13.0 \mathrm{~cm}$, neck $3.5 \mathrm{~cm}$, and height 
$5.0 \mathrm{~cm}), 7)$ a red can with relief $(12.0 \times 9.0 \times 9.0 \mathrm{~cm})$, and 8$)$ a round white cup with a handle (diameter $7.0 \mathrm{~cm}$ and height $9.5 \mathrm{~cm})$. A rat could not displace the objects.

A testing session started with the injection of the drugs. Thirty minutes later, a rat was subjected to the first trial (T1) which lasted 3 min. During T1 the apparatus contained two identical objects (samples). A rat was always placed in the apparatus facing the wall at the middle of the transparent segment. After the end of $\mathrm{T} 1$ the rat was put back in its home cage. After one hour the rat was put back in the apparatus for the second trial (T2), but now with two dissimilar objects, a familiar one (the sample) and a new one. The times spent in exploring each object during $\mathrm{T} 1$ and $\mathrm{T} 2$ were recorded manually with a personal computer.

Exploration was defined as follows: directing the nose to the object at a distance of no more than $2 \mathrm{~cm}$ and/or touching the object with the nose. Sitting on the object was not considered as exploratory behavior. In order to avoid the presence of olfactory trails the objects were always thoroughly cleaned. Also, there were three copies of each object. Since the familiar copy was not used in T1, the rat could not use olfactory cues to recognize the familiar object. All combinations and locations of objects were used in a balanced manner to reduce potential biases due to preferences for particular locations or objects.

In several studies it was shown that Wistar rats show a good object memory performance when a one-hour delay is interposed between the first and the second trial. However, when a $24 \mathrm{~h}$ delay is used the rats do not discriminate the novel and the familiar in the second trial, indicating that the rats do not remember the object that was presented in the first trial (e.g., Lieben et al., 2005; Prickaerts et al., 2005). Using a six hour delay, the discrimination performance is between the performance of the one hour and $24 \mathrm{~h}$ delay, suggesting a delaydependent forgetting in this task.

\subsection{Drug treatment}

Scopolamine hydrobromide, methyl-scopolamine, and nicotine were obtained from Sigma (Zwijndrecht, The Netherlands). Donepezil was received from Apin chemicals (Oxon, United Kingdom). Scopolamine $(0.1 \mathrm{mg} / \mathrm{kg})$, methyl-scopolamine $(0.1 \mathrm{mg} / \mathrm{kg})$, and nicotine $(0.1 \mathrm{mg} / \mathrm{kg})$ were freshly dissolved in saline and injected i.p. in a volume of $2 \mathrm{ml} / \mathrm{kg}$. Saline was also injected in the same volume i.p. Donepezil $(3 \mathrm{mg} / \mathrm{kg})$ was dissolved in MilliQ pure water and administered p.o. in a volume of $1 \mathrm{ml} / \mathrm{kg}$. Saline, scopolamine, methyl-scopolamine, and donepezil were administered $30 \mathrm{~min}$ before $\mathrm{T} 1$ and nicotine $20 \mathrm{~min}$ before $\mathrm{T} 1$.

Scopolamine, methyl-scopolamine, and saline treatments were performed twice. The results of those two measurements were later averaged.

\subsection{Analyses}

\subsubsection{EEG analysis}

First, EEG was visually checked offline for artifacts. AEPs generated by stimuli that were presented in the presence of artifacts were excluded from further analysis. The EEG fragments within an epoch of $100 \mathrm{~ms}$ before onset of a response and $1000 \mathrm{~ms}$ after response onset were averaged for all trials without artifacts. The mean amplitude of the $100 \mathrm{~ms}$ before stimulus onset was used as a baseline value (baseline correction).

The AEP components were determined on the basis of the individual (single animal) and grand average (over all animals) AEPs, taking both the latency and amplitude variables into account. The amplitude of the P1 component was defined as the maximum positive amplitude between 20 and $42 \mathrm{~ms}$ after stimulus onset, $\mathrm{N} 1$ as most negative value between 37 and $55 \mathrm{~ms}$ after tone onset, $\mathrm{P} 2$ as most positive between 60 and 80 , and $\mathrm{N} 2$ as most negative between 160 and $220 \mathrm{~ms}$.

Analyses of variance (ANOVA) was used for the analyses of each AEP component. Three main analyses were performed. First, the saline AEPs were compared to the scopolamine and methyl-scopolamine AEPs, using Treatment (3 levels) as within-subject factor. The second analysis comprised ANOVAs for the comparison of scopolamine with donepezil (4 levels: saline, scopolamine, donepezil, scopolamine+donepezil). In the final analysis, scopolamine was compared to nicotine (4 levels: saline, scopolamine, nicotine, scopolamine+nicotine). Post hoc analyses using least significant difference tests were performed to evaluate differences between conditions in more detail $(P<.05)$.

Next, we performed a frequency analysis on the data. After baseline correction was performed on the data (using the last $100 \mathrm{~ms}$ before stimulus onset), the EEG fragments from onset of the tone until $1000 \mathrm{~ms}$ after tone onset were included in a spectral analysis. The spectral content of the EEG was determined by Fast Fourier Transform (FFT, frequency resolution of $1 \mathrm{~Hz}$ ), with a Hamming correction. For each tone, the FFT was calculated. An average over stimuli was subsequently calculated. Only the absolute power of the theta frequency band $(5-10 \mathrm{~Hz})$ was used for statistical analysis. ANOVA's were calculated in a similar manner as the analyses for the AEP components.

\subsubsection{Behavioral analysis}

The basic measures were the times spent by rats in exploring an object during $\mathrm{T} 1$ and $\mathrm{T} 2$. The time spent in exploring the two identical samples will be represented by ' $a 1$ ' and ' $a 2$ '. The time spent in T2 in exploring the sample and new object will be represented by ' $a$ ' and ' $b$ ', respectively. The following variables were calculated: 1) Total exploration during $\mathrm{T} 1(e 1)=a 1+a 2,2)$ total exploration during T2 $(e 2)=a+b$ and 3) Discrimination score $(d 2)=\mathrm{b}-a / e 2$. The $d 2$ was considered as an index measure of discrimination between the new and the familiar objects. In fact, $d 2$ is a relative measure of discrimination that corrects for exploration activity $(e 2)$. Thus, there should be no differences in $d 2$ indices between experiments with similar treatments at similar intervals.

Effects between the different drug conditions were assessed using a one-way ANOVA. In case of a statistically reliable dose effect, comparisons between means of the different doses were analysed in more detail using post hoc least significant difference tests $(P<.05)$. 


\section{Results}

\subsection{Missing data}

Two animals were not used for the analysis, since the EEG was generally of too bad quality due to technical problems. Postmortem verification of the hippocampal electrode was performed in the other six animals. The brains were removed and coronal sections were cut. Next, they were stained using hematoxyline and eosine and inspected under a light microscope. In four out of six animals, the electrode was located in the dorsal hippocampus. In the other two, no electrode position could be located at all. However, the recordings of these two animals showed a reliable EEG signal with characteristic hippocampal EEG, comparable to the other rats.

\subsection{AEP components}

\subsubsection{Saline vs. scopolamine treatment}

Fig. 1A shows the hippocampal AEPs after saline, scopolamine and methyl-scopolamine treatment. Four main components are present: $\mathrm{P} 1, \mathrm{~N} 1, \mathrm{P} 2$, and N2. It can be noted that scopolamine decreases most of the amplitudes of the AEP components.

The ANOVAs did not show any significant effects with regard to the amplitudes of the AEP components. The N1, however, revealed a marginally significant effect of treatment $\left(F_{2,10}=3.58, P<0.07\right)$. The amplitude of the N1 was significantly increased after scopolamine compared to the saline condition $(P=0.03)$, as shown by the post-hoc analysis. Furthermore, the $\mathrm{N} 2$ revealed a marginally significant treatment effect $\left(F_{2,10}=3.57, P<0.07\right)$, which was indicated by a significant decrease in amplitude after scopolamine than after saline $(P=0.02)$.

The latencies of the components were not affected by drug treatment.

\subsubsection{Donepezil treatment}

Fig. 1B shows the AEPs after the saline, scopolamine, donepezil and scopolamine + donepezil treatment conditions. Donepezil treatment did not reverse scopolamine-induced changes in the amplitudes of the AEP components.

The P1 component was not affected by donepezil treatment. Treatment did significantly affect the N1 $\left(F_{3,15}=8.04, P<0.01\right)$. Post-hoc analysis revealed that the N1 was larger after scopolamine and after scopolamine + donepezil treatment as compared with saline. Furthermore, the scopolamine+donepezil amplitude was larger than the donepezil amplitude.

The P2 component of the AEP was not affected by treatment. Treatment did have an effect on the amplitude of the N2 $\left(F_{3,15}=8.17, P<0.01\right)$. Post-hoc analysis showed that the scopolamine $\mathrm{N} 2$ amplitude was decreased compared to the saline and donepezil treatment. Furthermore, N2 was larger to the donepezil than to the scopolamine+donepezil component.

The ANOVAs for the latencies of the components revealed no drug effects.

\subsubsection{Nicotine treatment}

The AEPs after saline, scopolamine, nicotine and scopolamine + nicotine treatment are shown in Fig. 1C. As was the case for the donepezil treatment, nicotine treatment was not able to reverse the scopolamine-induced effects.

The ANOVA for the AEP N2 component was the only component to show a significant amplitude effect $\left(F_{3,15}=3.38\right.$, $P<0.05)$. Post-hoc analysis revealed that scopolamine elicited smaller N2 amplitudes than did saline and nicotine treatments.

None of the latencies of the AEP were affected.
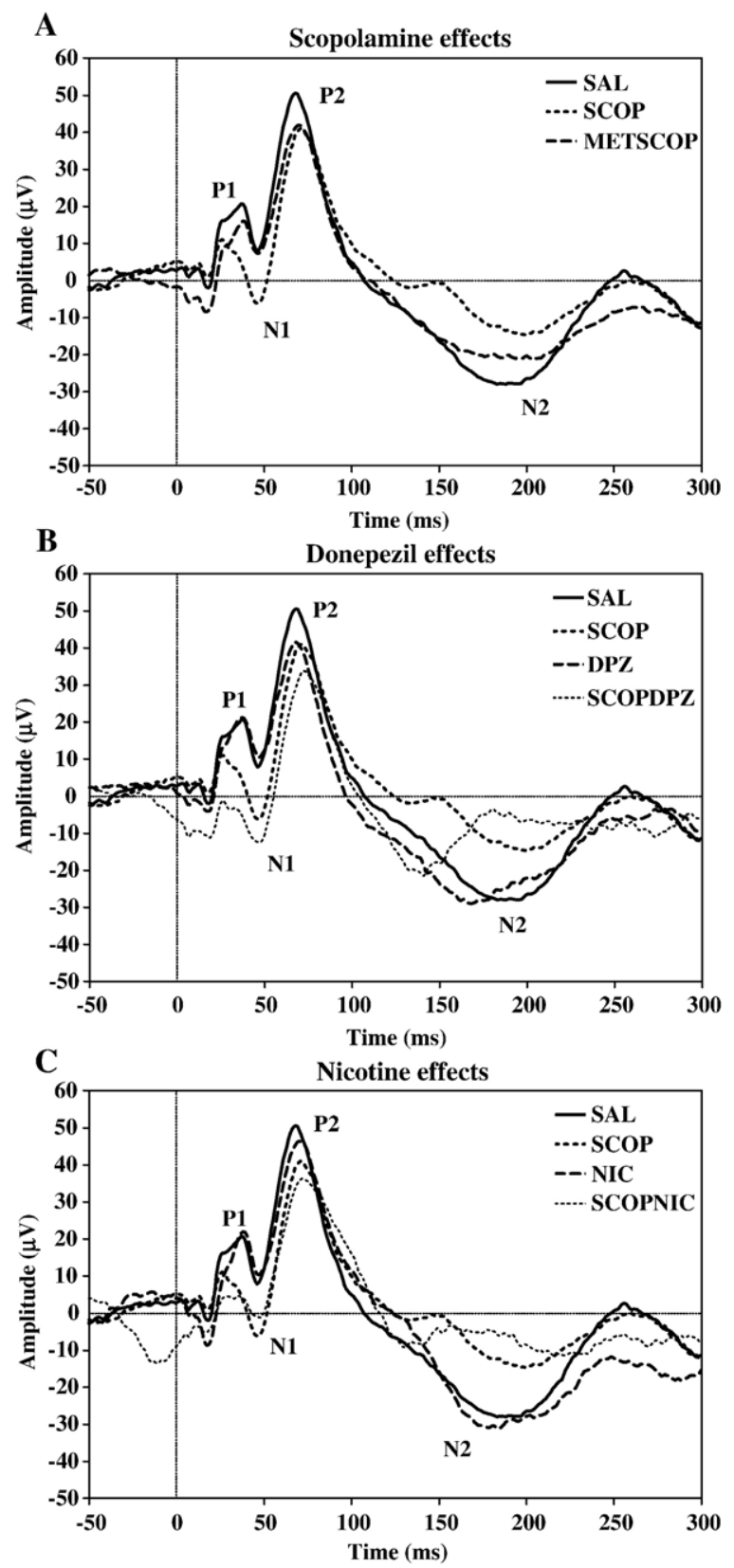

Fig. 1. Hippocampal grand average AEPs after scopolamine (1A), donepezil (1B), and nicotine (1C) treatments. Latencies are shown on the $x$-axis in milliseconds and amplitudes are presented on the $y$-axis in microvolts. Note that four AEP components were present, which are nominated P1, N1, P2, and N2. 

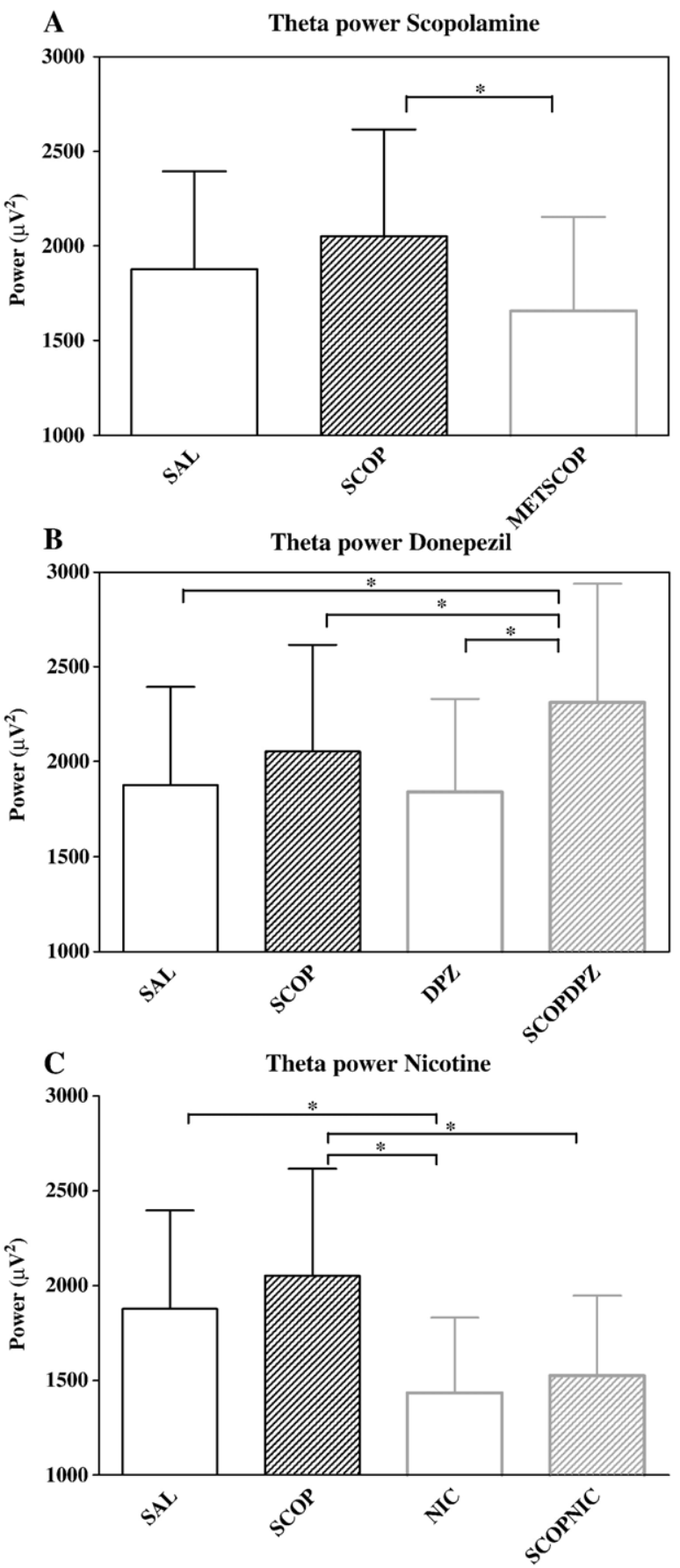

Fig. 2. Absolute theta power (and standard error) in response to auditory stimuli after scopolamine (2A), donepezil (2B), and nicotine (2C) treatments. The power is represented as square microvolts $\left(\mu \mathrm{V}^{2}\right)$.

\subsection{Frequency analyses}

\subsubsection{Saline vs. scopolamine treatment}

Fig. 2A shows the absolute theta power during auditory stimuli, for the scopolamine treatment. The ANOVA revealed a significant treatment effect $\left(F_{2,10}=6.16, P<0.03\right)$. Post-hoc analysis showed that theta power was larger after scopolamine than after methyl-scopolamine treatment.

\subsubsection{Donepezil treatment}

Theta power after donepezil treatment can be seen in Fig. 2B. It was significantly affected by treatment $\left(F_{3,15}=7.46\right.$, $P<0.01)$. Post-hoc tests revealed that combined scopolamine and donepezil treatment elicited larger theta power than did the other three treatment conditions. There were no differences between saline, scopolamine, and donepezil.
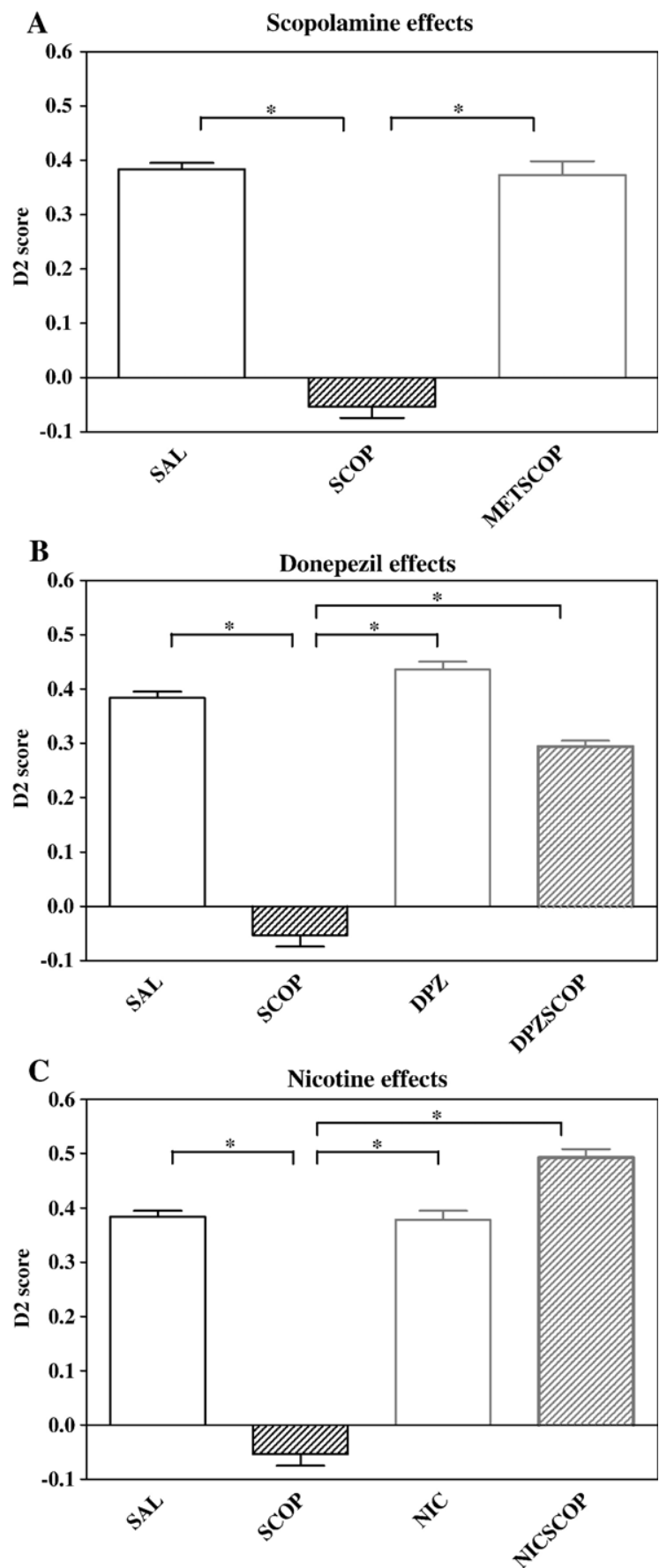

Fig. 3. Discrimination (D2) scores (and standard error) from the second trial of the object recognition task, for scopolamine (3A), donepezil (3B), and nicotine (3C) treatments. 


\subsubsection{Nicotine treatment}

Fig. $2 \mathrm{C}$ illustrates the theta power after nicotine treatment. The ANOVA showed a significant treatment effect $\left(F_{3,15}=6.58\right.$, $P<0.01)$. Theta power was decreased after nicotine treatment compared to saline and scopolamine, as shown by the post-hoc test. Furthermore, combined scopolamine and nicotine theta power was decreased compared to scopolamine alone.

\subsection{Object recognition task}

\subsubsection{Saline vs. scopolamine treatment}

$e 1$ during the first trial was significantly affected by treatment $\left(F_{2,47}=5.42, P<0.01\right)$. Post-hoc analysis showed that exploration was larger after saline than after the other two treatments. Exploration during Trial 2 did not differ between treatments $\left(F_{2,47}=0.34\right.$, n.s. $)$.

Fig. 3A shows the $d 2$ score of the animals in the second trial of the object recognition task after saline, scopolamine, and methyl-scopolamine. The ANOVA revealed a significant treatment effect $\left(F_{2,47}=11.78, P<0.001\right)$. The $d 2$ score was decreased in the scopolamine condition compared to both the saline and the methyl-scopolamine conditions, as shown by the post-hoc analysis. Saline and methyl-scopolamine $d 2$ scores did not differ.

\subsubsection{Donepezil treatment}

Treatment did not significantly affect $e 1\left(F_{3,70}=2.51\right.$, n.s. $)$ and $e 2\left(F_{3,70}=1.36\right.$, n.s. $)$ exploration scores.

Fig. 3B illustrates the $d 2$ score after donepezil treatments. A significant treatment effect was found $\left(F_{3,70}=10.21, P<0.001\right)$. This was due to decreased $d 2$ scores in the scopolamine condition compared to the other three treatments. Donepezil, thus, reversed the decrement in $d 2$ score induced by scopolamine.

\subsubsection{Nicotine treatment}

A significant treatment effect was found with regard to $e 1$ $\left(F_{3,57}=2.84, P<0.05\right)$. Exploration was larger after saline than after scopolamine and nicotine treatments, but saline and nicotine+scopolamine did not differ in exploration time, as shown by a post-hoc analysis. Exploration during the second trial (e2) did not significantly differ $\left(F_{3,57}=0.65\right.$, n.s. $)$.

$d 2$ scores after nicotine treatments can be seen in Fig. 3C. A significant treatment effect was present $\left(F_{3,57}=12.86\right.$, $P<0.001)$. Post-hoc analysis revealed that the $d 2$ score was smaller after scopolamine compared to the other treatments, which indicated that nicotine reversed the scopolamine induced $d 2$ decrement.

\section{Discussion}

The aim of this study was to assess whether drug effects on memory can be related to drug effects on EEG in rats. We examined the effects of scopolamine, methyl-scopolamine, donepezil, and nicotine on object recognition and AEPs in two groups of animals. Object recognition was impaired after treatment with scopolamine, but not after methyl-scopolamine.
Both donepezil and nicotine were able to reverse this impairment. With regard to the AEPs, scopolamine increased the amplitude of the $\mathrm{N} 1$ component, but decreased the N2 component amplitude. Neither donepezil nor nicotine was able to reverse these AEP effects. Scopolamine increased theta frequency. When combined with donepezil, theta was even more increased. Nicotine, on the other hand, was able to reverse this theta increment, as was shown by the decrement in theta when scopolamine and nicotine were combined as compared to the scopolamine treatment alone.

Not unexpectedly, the current findings that scopolamine but not methyl-scopolamine impaired object recognition, are in accordance with previous research in animals (Blokland, 1995; Cosquer et al., 2005; Dodart et al., 1997; Woolley et al., 2003) and humans (Ebert and Kirch, 1998; Schon et al., 2005; Sherman et al., 2003).

In our study, scopolamine increased the theta frequency 30 min after treatment as compared to the methyl-scopolamine treatment. This corresponds to most animal (Dimpfel, 2005; Masuoka et al., 2006) and human (Ebert et al., 1998; Sannita et al., 1987; Sloan et al., 1992) data. Only Kinney and colleagues (1999) showed a decrement in theta after scopolamine in urethane-anesthetized animals, possibly because the anesthesia interacted with the scopolamine.

Hippocampal theta is related to motor activation or active sniffing behavior in rats and may lead to the formation of memories (Buzsaki, 2005; Vanderwolf, 1969, 1992). Theta frequency in humans, which is usually measured from the scalp, may however be related to both specific types of activation (such as seen during concentration in a chess-game) or drowsiness (e.g., Smit et al., 2004; Burgess and Gruzelier, 2000; Klimesch et al., 2000). It has been suggested that theta increments are due to a decline of information processing (Smit, 2004; Klimesch et al., 2000). In the case of a vigilance decrement, information processing in general is diminished due to lowered arousal, whereas only irrelevant information processing is diminished in the case of specific activation. Both situations may lead to increments in theta activity, which may make it difficult to compare rat data to those in humans. Considering that changes in theta frequency in animals are due to the same processes as proposed in humans, the increment in theta activity after scopolamine treatment in the present study may be due to 1) a decline of information processing other than the auditory stimuli presented and 2) a general arousal decrement after scopolamine.

At the dose used, methyl-scopolamine did not change theta frequency in the current experiment. To our knowledge, the effect of methyl-scopolamine on EEG frequencies has not been studied so far in rats. On the other hand, since methylscopolamine crosses the blood-brain barrier only to a limited extent (Moore et al., 1992), such a lack of an effect could be expected. One study in humans (Sloan et al., 1992) showed that methyl-scopolamine did not affect EEG activity, a result comparable to ours.

Next to the effects on the EEG, we examined the effects of scopolamine on the rat AEP. Scopolamine increased the N1, but decreased the N2 component. A closer look at the AEPs (see 
Fig. 1), however, reveals that the amplitudes of both components became closer to baseline $(0 \mathrm{mV})$ after scopolamine. This is similar to an effect previously found after repeated auditory stimulation in rats (Sambeth and Maes, 2006; Sambeth et al., 2004). Thus, it may be concluded that both components decreased in amplitude after scopolamine treatment in our study (see also Campbell et al., 1995). In our study, methyl-scopolamine did not affect the AEP components, as was found in the study of Campbell and colleagues as well (Campbell et al., 1995).

In sum, scopolamine, but not methyl-scopolamine, impaired object recognition, reduced the amplitudes of the N1 and N2 components, and increased theta activity. These data underscore the notion that the changes after scopolamine are due to its central action in the brain, rather than an effect on the peripheral muscarinic receptors.

One possible explanation of these results might be that they are due to a drop in arousal after scopolamine. Scopolamine is known to decrease vigilance and impair attention processes in humans (Ellis et al., 2006; Kamboj and Curran, 2006; Koller et al., 2003; Mintzer and Griffiths, 2003). The impairments in object recognition and the decrease in N1 and N2 amplitudes found in the current study could be explained by those arousal processes. Furthermore, theta frequency was increased in the hippocampus, which can be a result of the arousal decrement as well.

Even though some evidence is in favor of a decrement in arousal in this experiment, other studies in which acetylcholine was manipulated using scopolamine have argued against this possibility (Curran et al., 1998; Molchan et al., 1992; Sloan et al., 1992). For instance, scopolamine did not significantly affect the latencies of several visual evoked potential components in humans although they are susceptible to drowsiness effects (Sloan et al., 1992). Furthermore, sedative effects of scopolamine are often independent from effects on memory (Curran et al., 1998; Molchan et al., 1992). Future research, in which effects on memory, attention, and arousal will have to be directly compared, will shed more light into the specificity of the effects found in the present study.

In this experiment, the drugs that increased acetylcholine were able to reverse the scopolamine-induced object recognition impairment, which is in line with other work showing that donepezil and nicotine can improve memory performance in rats (Barros et al., 2005; Prickaerts et al., 2005; Yamada et al., 2005). Thus, this again shows that both the muscarinic and the nicotinic cholinergic receptors play a role in memory processing (for reviews, see Gold, 2003; Levin et al., 2006; Parent and Baxter, 2004). Furthermore, the fact that nicotine reversed the scopolamine-induced impairment suggests that the nicotinic and muscarinic receptors functionally interact in their effect on memory (see also Green et al., 2005).

It must be noted that high doses of scopolamine may not only have an effect on the muscarinic receptors, but also on the nicotinic receptors (Schmeller et al., 1995). In the current experiment, we only used a relatively low dose of $0.1 \mathrm{mg} / \mathrm{kg}$ as opposed to other studies where doses of between 0.25 and $1 \mathrm{mg} / \mathrm{kg}$ have been administered (Dimpfel, 2005; van der Staay and Bouger, 2005; Bejar et al., 1999; Kinney et al., 1999; Campbell et al., 1995). It is therefore, not likely that nicotine reversed the scopolamine-induced impairments because of scopolamine's effect on the nicotinic receptor.

Neither donepezil, nor nicotine, was able to reverse the effects of scopolamine on the $\mathrm{N} 1$ and $\mathrm{N} 2$ components of the AEP. These findings suggest that the drug effects on the AEP and the memory performance are independent and argue against a relation between these two parameters. Thus, although scopolamine affects both the AEP and the object memory performance, a dissociation between these effects was found after treatment with donepezil and nicotine.

Donepezil did not reverse the scopolamine-induced increase in hippocampal theta frequency, whereas nicotine did. Actually, donepezil combined with scopolamine resulted in an even larger increment of theta compared to scopolamine treatment alone. The fact that both scopolamine (Dimpfel, 2005; Masuoka et al., 2006) and donepezil (Kinney et al., 1999) increase theta activity when given separately might explain this current effect. However, in the study of Kinney et al. (Kinney et al., 1999) theta increment after donepezil was reversed by scopolamine. As mentioned earlier, the discrepancy between the data is likely to be explained by the urethane-anesthesia used in the study by Kinney and colleagues.

Above, it was proposed that scopolamine decreased arousal level, which in turn increased theta activity. If this is indeed the case, then the effect on theta activity by nicotine shows that it is able to increase arousal. After all, theta frequency did not differ between nicotine and the scopolamine-nicotine combination, and, was smaller than after scopolamine alone. However, a stabilization of the arousal level due to nicotine should have increased the N1 and N2 components, which it did not do. Therefore, nicotine was only partly able to reverse the scopolamine-induced arousal decrement. Given the effects of donepezil on the AEP components and theta frequency in the current experiment, we would conclude that donepezil did not reverse a scopolamine-induced decrement in arousal at all.

An explanation for the difference in effects after donepezil and nicotine treatment may come from the fact that nicotine binds to nicotinic acetylcholine receptors, which may lead to an increase in dopamine levels in the brain (Turner, 2004; Wonnacott, 1997; Wang et al., 2007). Donepezil only inhibits the acetylcholinesterase (for review see Seltzer, 2007), leading to enhanced acetylcholine levels in general. Possibly, arousal levels were partly increased after nicotine treatment because of an increase in dopamine rather than acetylcholine in general, and thus, the nicotinic receptors may be more important than muscarinic receptors with respect to arousal. Further research is needed to test this hypothesis.

In conclusion, scopolamine impaired object recognition and affected hippocampal EEG (AEP and theta power). Although these data alone may suggest a relation between memory performance and EEG, the findings of the additional drugs donepezil and nicotine caution such a simple conclusion. There was a clear dissociation between memory performance and EEG after combined treatment with drugs. Apparently, drug effects on behavior and EEG are dissociable on basis of 
different processes. Further studies are indicated in which taskrelated EEG measures are associated with memory performance. Such studies may further explore the possibility to use EEG measures for translational studies.

\section{Acknowledgements}

The authors acknowledge that the current experiment complies with the principles of laboratory animal care in accordance with the Dutch law. Furthermore, the authors have no financial interest in or financial conflict with the subject matter or materials discussed in the manuscript.

\section{References}

Barros, D.M., Ramirez, M.R., Izquierdo, I., 2005. Modulation of working, shortand long-term memory by nicotinic receptors in the basolateral amygdala in rats. Neurobiol. Learn. Mem. 83, 113-118.

Bejar, C., Wang, R.H., Weinstock, M., 1999. Effect of rivastigmine on scopolamineinduced memory impairment in rats. Eur. J. Pharmacol. 383, 231-240.

Birks, J., 2006. Cholinesterase inhibitors for Alzheimer's disease. Cochrane Database Syst. Rev 25, 1-80.

Blokland, A., 1995. Acetylcholine: a neurotransmitter for learning and memory? Brain Res. Rev. 21, 285-300.

Broadbent, N.J., Squire, L.R., Clark, R.E., 2004. Spatial memory, recognition memory, and the hippocampus. Proc. Natl. Acad. Sci. U. S. A. 101, $14515-14520$.

Burgess, A.P., Gruzelier, J.H., 2000. Short duration power changes in the EEG during recognition memory for words and faces. Psychophysiology 37, 596-606.

Buzsaki, G., 2005. Theta rhythm of navigation: link between path integration and landmark navigation, episodic and semantic memory. Hippocampus 15 , 827-840.

Campbell, K.A., Kalmbacher, C.E., Specht, C.D., Gregg, T.R., 1995. Dependence of rat vertex auditory evoked potentials on central muscarinic receptor activation. Brain Res. 702, 110-116.

Clark, R.E., Zola, S.M., Squire, L.R., 2000. Impaired recognition memory in rats after damage to the hippocampus. J. Neurosci. 20, 8853-8860.

Coenen, A.M., Van Luijtelaar, E.L., 2003. Genetic animal models for absence epilepsy: a review of the WAG/Rij strain of rats. Behav. Genet. 33, 635-655.

Cosquer, B., Vasconcelos, A.P., Frohlich, J., Cassel, J.C., 2005. Blood-brain barrier and electromagnetic fields: effects of scopolamine methylbromide on working memory after whole-body exposure to $2.45 \mathrm{GHz}$ microwaves in rats. Behav. Brain Res. 161, 229-237.

Curran, H.V., Pooviboonsuk, P., Dalton, J.A., Lader, M.H., 1998. Differentiating the effects of centrally acting drugs on arousal and memory: an event-related potential study of scopolamine, lorazepam and diphenhydramine. Psychopharmacology $135,27-36$.

Dimpfel, W., 2005. Pharmacological modulation of cholinergic brain activity and its reflection in special EEG frequency ranges from various brain areas in the freely moving rat (Tele-Stereo-EEG). Eur. Neuropsychopharmacol. 15, 673-682.

Dimpfel, W., Spuler, M., Wessel, K., 1992. Different neuroleptics show common dose and time dependent effects in quantitative field potential analysis in freely moving rats. Psychopharmacology 107, 195-202.

Dodart, J.C., Mathis, C., Ungerer, A., 1997. Scopolamine-induced deficits in a two-trial object recognition task in mice. Neuroreport 8, 1173-1178.

Ebert, U., Kirch, W., 1998. Scopolamine model of dementia: electroencephalogram findings and cognitive performance. Eur. J. Clin. Investig. 28, 944-949.

Ebert, U., Oertel, R., Wesnes, K.A., Kirch, W., 1998. Effects of physostigmine on scopolamine induced changes in quantitative electroencephalogram and cognitive performance. Hum. Psychopharmacol. 13, 199-210.

Ellis, J.R., Ellis, K.A., Bartholomeusz, C.F., Harrison, B.J., Wesnes, K.A., Erskine, F.F., Vitetta, L., Nathan, P.J., 2006. Muscarinic and nicotinic receptors synergistically modulate working memory and attention in humans. Int. J. Neuropsychopharmacol. 9, 175-189.
Gold, P.E., 2003. Acetylcholine modulation of neural systems involved in learning and memory. Neurobiol. Learn. Mem. 80, 194-210.

Green, A., Ellis, K.A., Ellis, J., Bartholomeusz, C.F., Ilic, S., Croft, R.J., Luan Phan, K., Nathan, P.J., 2005. Muscarinic and nicotinic receptor modulation of object and spatial n-back working memory in humans. Pharmacol. Biochem. Behav. 81, 575-584.

Jongsma, M.L., Van Rijn, C.M., De Bruin, E.A., Dirksen, R., Coenen, A.M., 1998a. Time course of chronic diazepam effects on the auditory evoked potential of the rat. Eur. J. Pharmacol. 341, 153-160.

Jongsma, M.L., Van Rijn, C.M., Setz, A., Smit, A., Berben, I., Dirksen, R., Coenen, A.M., 1998b. Effects of diazepam on auditory evoked potentials (AEPs) and omission evoked potentials (OEPs) in rats and students. SleepWake Res. Neth. 9, 65-72.

Kamboj, S.K., Curran, H.V., 2006. Scopolamine induces impairments in the recognition of human facial expressions of anger and disgust. Psychopharmacology 185, 529-535.

Kinney, G.G., Patino, P., Mermet-Bouvier, Y., Starrett Jr., J.E., Gribkoff, V.K., 1999. Cognition-enhancing drugs increase stimulated hippocampal theta rhythm amplitude in the urethane-anesthetized rat. J. Pharmacol. Exp. Ther. 291, 99-106.

Klimesch, W., Doppelmayr, M., Schwaiger, J., Winkler, T., Gruber, W., 2000. Theta oscillations and the ERP old/new effect: independent phenomena? Clin. Neurophysiol. 111, 781-793.

Koller, G., Satzger, W., Adam, M., Wagner, M., Kathmann, N., Soyka, M., Engel, R., 2003. Effects of scopolamine on matching to sample paradigm and related tests in human subjects. Neuropsychobiology 48, 87-94.

Levin, E.D., McClernon, F.J., Rezvani, A.H., 2006. Nicotinic effects on cognitive function: behavioral characterization, pharmacological specification, and anatomic localization. Psychopharmacology 184, 523-539.

Lieben, C.K., Blokland, A., Sik, A., Sung, E., van Nieuwenhuizen, P., Schreiber, R., 2005. The selective 5-HT6 receptor antagonist Ro4368554 restores memory performance in cholinergic and serotonergic models of memory deficiency in the rat. Neuropsychopharmacology 30, 2169-2179.

Masuoka, T., Fujii, Y., Kamei, C., 2006. Effect of scopolamine on the hippocampal theta rhythm during an eight-arm radial maze task in rats. Eur. J. Pharmacol. 539, 76-80.

Mintzer, M.Z., Griffiths, R.R., 2003. Lorazepam and scopolamine: A singledose comparison of effects on human memory and attentional processes. Exp. Clin. Psychopharmacol. 11, 56-72.

Molchan, S.E., Martinez, R.A., Hill, J.L., Weingartner, H.J., Thompson, K., Vitiello, B., Sunderland, T., 1992. Increased cognitive sensitivity to scopolamine with age and a perspective on the scopolamine model. Brain Res. Rev. 17, 215-226.

Moore, H., Dudchenko, P., Comer, K.S., Bruno, J.P., Sarter, M., 1992. Central versus peripheral effects of muscarinic antagonists: the limitations of quarternary ammonium derivatives. Psychopharmacology 108, 241-243.

Mumenthaler, M.S., Yesavage, J.A., Taylor, J.L., O’Hara, R., Friedman, L., Lee, H., Kraemer, H.C., 2003. Psychoactive drugs and pilot performance: a comparison of nicotine, donepezil, and alcohol effects. Neuropsychopharmacology 28, 1366-1373.

Parent, M.B., Baxter, M.G., 2004. Septohippocampal acetylcholine: involved in but not necessary for learning and memory? Learn. Mem. 11, 9-20.

Prickaerts, J., De Vente, J., Honig, W., Steinbusch, H.W.M., Blokland, A., 2002a. cGMP, but not cAMP, in rat hippocampus is involved in early stages of object memory consolidation. Eur. J. Pharmacol. 436, 83-87.

Prickaerts, J., van Staveren, W.C., Sik, A., Markerink-van Ittersum, M., Niewohner, U., van der Staay, F.J., Blokland, A., de Vente, J., 2002b. Effects of two selective phosphodiesterase type 5 inhibitors, sildenafil and vardenafil, on object recognition memory and hippocampal cyclic GMP levels in the rat. Neuroscience 113, 351-361.

Prickaerts, J., Sik, A., van der Staay, F.J., de Vente, J., Blokland, A., 2005. Dissociable effects of acetylcholinesterase inhibitors and phosphodiesterase type 5 inhibitors on object recognition memory: acquisition versus consolidation. Psychopharmacology 177, 381-390.

Sambeth, A., Maes, J.H., 2006. A comparison of event-related potentials of humans and rats elicited by a serial feature-positive discrimination task. Learn. Motiv. 37, 269-288. 
Sambeth, A., Maes, J.H., Van Luijtelaar, G., Molenkamp, I.B., Jongsma, M.L., Van Rijn, C.M., 2003. Auditory event-related potentials in humans and rats: effects of task manipulation. Psychophysiology 40, 60-68.

Sambeth, A., Maes, J.H., Quian Quiroga, R., Coenen, A.M., 2004. Effects of stimulus repetitions on the event-related potential of humans and rats. Int. J. Psychophysiol. 53, 197-205.

Sannita, W.G., Maggi, L., Rosadini, G., 1987. Effects of scopolamine (0.25$0.75 \mathrm{mg}$ i.m.) on the quantitative EEG and the neuropsychological status of healthy volunteers. Neuropsychobiology 17, 199-205.

Schmeller, T., Sporer, F., Sauerwein, M., Wink, M., 1995. Binding of tropane alkaloids to nicotinic and muscarinic acetylcholine receptors. Pharmazie 50, 493-495.

Schon, K., Atri, A., Hasselmo, M.E., Tricarico, M.D., LoPresti, M.L., Stern, C. E., 2005. Scopolamine reduces persistent activity related to long-term encoding in the parahippocampal gyrus during delayed matching in humans. J. Neurosci. 25, 9112-9123.

Seltzer, B., 2007. Donepezi: an update. Expert Opin. Pharmacother. 8, $1011-1023$

Sherman, S.J., Atri, A., Hasselmo, M.E., Stern, C.E., Howard, M.W., 2003 Scopolamine impairs human recognition memory: data and modeling. Behav. Neurosci. 117, 526-539.

Sloan, E.P., Fenton, G.W., Standage, K.P., 1992. Anticholinergic drug effects on quantitative electroencephalogram, visual evoked potential, and verbal memory. Biol. Psychiatry 31, 600-606.

Smit, A.S., 2004. Vigilance or availability of processing resources. A study on cognitive energetics. Doctoral dissertation Radboud University, Nijmegen, the Netherlands

Smit, A.S., Eling, P.A.T.M., Coenen, A.M.L., 2004. Mental effort affects vigilance enduringly: after-effects in EEG and behavior. Int. J. Psychophysiol. 53, 239-243.

Snyder, P., Bednar, M., Cromer, J., Maruff, P., 2005. Reversal of scopolamineinduced deficits with a single dose of donepezil, an acetylcholinesterase inhibitor. Alz. Dem. 1, 126-135.
Turner, T.J., 2004. Nicotine enhancement of dopamine release by a calciumdependent increase in the size of the readily releasable pool of synaptic vesicles. J. Neurosci. 24, 11328-11336.

van der Staay, F.J., Bouger, P.C., 2005. Effects of the cholinesterase inhibitors donepezil and metrifonate on scopolamine-induced impairments in the spatial cone field orientation task in rats. Behav. Brain Res. 156, 1-10.

Vanderwolf, C.H., 1969. Hippocampal electrical activity and voluntary movement in the rat. Electroencephalogr. Clin. Neurophysiol. 26, 407-418.

Vanderwolf, C.H., 1992. The electrocorticogram in relation to physiology and behavior: a new analysis. Electroencephalogr. Clin. Neurophysiol. 82, $165-175$.

Wang, D., Noda, Y., Zhou, Y., Mouri, A., Mizoguchi, H., Nitta, A., Chen, W., Nabeshima, T., 2007. The allosteric potentiation of nicotnic acetylcholine receptors by galantamine ameliorates the cognitive dysfunction in beta amyloid25-35 i.c.v.-injected mice: involvement of dopaminergic systems. Neuropsychopharmacology 32, 1261-1271.

Wezenberg, E., Verkes, R.J., Sabbe, B.G., Ruigt, G.S., Hulstijn, W., 2005. Modulation of memory and visuospatial processes by biperiden and rivastigmine in elderly healthy subjects. Psychopharmacology 181, 582-594.

Wonnacott, S., 1997. Presynaptic nicotinic ACh receptors. Trends Neurosci. 20, 92-98.

Woolley, M.L., Marsden, C.A., Sleight, A.J., Fone, K.C., 2003. Reversal of a cholinergic-induced deficit in a rodent model of recognition memory by the selective 5-HT6 receptor antagonist, Ro 04-6790. Psychopharmacology $170,358-367$.

Yamada, K., Takayanagi, M., Kamei, H., Nagai, T., Dohniwa, M., Kobayashi, K., Yoshida, S., Ohhara, T., Takuma, K., Nabeshima, T., 2005. Effects of memantine and donepezil on amyloid beta-induced memory impairment in a delayed-matching to position task in rats. Behav. Brain Res. 162, 191-199.

Yoo, J.H., Valdovinos, M.G., Williams, D.C., in press. Relevance of donepezil in enhancing learning and memory in special populations: a review of the literature. J. Autism Dev. Disord. doi:10.1007/s.10803-006-0322-8. 